\title{
Clinical impact and cost-effectiveness of integrating smoking cessation into lung cancer screening: a microsimulation model
}

\author{
William K. Evans MD, Cindy L. Gauvreau PhD, William M. Flanagan BM, Saima Memon MBBS MPH, \\ Jean Hai Ein Yong MASc, John R. Goffin MD, Natalie R. Fitzgerald MA, Michael Wolfson PhD, \\ Anthony B. Miller MD
}

Abstract

Background: Low-dose computed tomography (CT) screening can reduce lung cancer mortality in people at high risk; adding a smoking cessation intervention to screening could further improve screening program outcomes. This study aimed to assess the impact of adding a smoking cessation intervention to lung cancer screening on clinical outcomes, costs and cost-effectiveness.

Methods: Using the OncoSim-Lung mathematical microsimulation model, we compared the projected lifetime impact of a smoking cessation intervention (nicotine replacement therapy, varenicline and 12 wk of counselling) in the context of annual low-dose CT screening for lung cancer in people at high risk to lung cancer screening without a cessation intervention in Canada. The simulated population consisted of Canadians born in 1940-1974; lung cancer screening was offered to eligible people in 2020. In the basecase scenario, we assumed that the intervention would be offered to smokers up to 10 times; each intervention would achieve a $2.5 \%$ permanent quit rate. Sensitivity analyses varied key model inputs. We calculated incremental cost-effectiveness ratios with a lifetime horizon from the health system's perspective, discounted at 1.5\% per year. Costs are in 2019 Canadian dollars.

Results: Offering a smoking cessation intervention in the context of lung cancer screening could lead to an additional $13 \%$ of smokers quitting smoking. It could potentially prevent 12 more lung cancers and save 200 more life-years for every 1000 smokers screened, at a cost of $\$ 22000$ per quality-adjusted life-year (QALY) gained. The results were most sensitive to quit rate. The intervention would cost over $\$ 50000$ per QALY gained with a permanent quit rate of less than $1.25 \%$ per attempt.

Interpretation: Adding a smoking cessation intervention to lung cancer screening is likely cost-effective. To optimize the benefits of lung cancer screening, health care providers should encourage participants who still smoke to quit smoking.

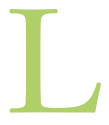

ung cancer is the leading cause of death from cancer in Canada. ${ }^{1}$ Low-dose computed tomography (CT) screening has been shown to reduce lung cancer mortality and is now recommended for people at high risk..$^{2-5} \mathrm{In}$ addition to early detection of lung cancer, a low-dose CT screening program provides an opportunity to help current smokers quit and to support those who have recently quit, as the encounter with the screening program is a teachable moment and an opportunity to refer patients for assistance with smoking cessation. ${ }^{6-8}$ Using data from the National Lung Screening Trial, ${ }^{2}$ Tanner and colleagues ${ }^{9}$ estimated that screening and 15 years of abstinence would almost double the mortality risk reduction from lung cancer screening alone.

Several clinical trials are underway to test the impact of various smoking cessation interventions in the context of low-dose CT screening, but their results will not be available soon..$^{10}$ In the interim, simulation models can help to address the evidence gaps and inform decisions regarding implementation of low-dose CT screening. In this study, we aimed to estimate the impact of adding a smoking cessation intervention to a low-dose CT screening program on long-term clinical benefits, health system costs and costeffectiveness using a microsimulation model.

\section{Methods}

\section{Population}

In this analysis, we simulated a cohort of people born in 1940-1974 in Canada and compared their lifetime outcomes. To compare addition of a smoking cessation intervention with no intervention in the context of low-dose CT screening, we modelled a low-dose CT screening program for people at high risk in Canada starting in 2020 using the eligibility criteria for age and smoking history recommended by the Canadian Task Force on Preventive Health Care $^{3}$ (Table 1). Participants were screened annually in the model as long as they met the eligibility criteria.

Competing interests: None declared.

This article has been peer reviewed.

Correspondence to: John Goffin, goffin@ mcmaster.ca

CMAJ Open 2020. DOI:10.9778/cmajo.20190134 


\begin{tabular}{|c|c|c|c|}
\hline Input & Base case & $\begin{array}{l}\text { Sensitivity } \\
\text { analysis }\end{array}$ & Source \\
\hline \multicolumn{4}{|l|}{ Screening program } \\
\hline Start year & \multicolumn{2}{|l|}{2020} & \\
\hline Eligibility criteria* & \multicolumn{2}{|l|}{$\begin{array}{l}\cdot \text { Age 55-74 yr } \\
\bullet \geq 30 \text { pack-year } \\
\text { smoking history }\end{array}$} & $\begin{array}{l}\text { Canadian Task Force } \\
\text { on Preventive Health } \\
\text { Care }^{3}\end{array}$ \\
\hline Recruitment rate, $\%$ & 40 & $20-60$ & $\begin{array}{l}\text { Canadian Partnership } \\
\text { Against Cancer }\end{array}$ \\
\hline Phase-in period, yr & 10 & - & \\
\hline Adherence rate, $\%$ & 70 & $50-90$ & \\
\hline \multicolumn{4}{|l|}{$\begin{array}{l}\text { Smoking cessation } \\
\text { intervention }\end{array}$} \\
\hline $\begin{array}{l}\text { Maximum no. of smoking } \\
\text { cessation attempts }\end{array}$ & 10 & $3-20$ & \\
\hline Quit rate, per attempt, \% & 2.5 & $1-10$ & laccarino et al., $2019^{12}$ \\
\hline $\begin{array}{l}\text { Smoking cessation intervention } \\
\text { cost, per person, } \$ \dagger\end{array}$ & 630 & $252-945$ & $\begin{array}{l}\text { Tulloch et al., } 2016^{13} \\
\text { Mullen et al., } 2015^{14}\end{array}$ \\
\hline $\begin{array}{l}\text { Lifetime cost of lung cancer } \\
\text { treatment, } \$ \ddagger\end{array}$ & 67100 & - & Seung et al., $2019^{15}$ \\
\hline \multicolumn{4}{|c|}{$\begin{array}{l}{ }^{*} \text { Current smokers and former smokers who had quit no more than } 15 \text { years earlier and had no prior history of lung cancer. } \\
\text { †The smoking cessation intervention costs were varied from base cost (by } 40 \%, 60 \%, 120 \%, 150 \%) \text { because drug prices } \\
\text { and personnel costs can vary by institution and province. Depending on the level of nicotine addiction, less-intensive and } \\
\text { less-costly interventions might also be used in practice. The costs of less-intensive smoking cessation interventions } \\
\text { include different combinations of nicotine replacement therapy, varenicline and counselling. } \\
\text { łSee Appendix } 1 \text {, section C, for more details. }\end{array}$} \\
\hline
\end{tabular}

\section{Simulation model}

We conducted the analysis using OncoSim-Lung version 3.3.1 (Canadian Partnership Against Cancer). OncoSim-Lung is a mathematical lung cancer microsimulation model. ${ }^{16,17}$ Briefly, the model simulates the smoking behaviour of the Canadian population, and the lifetime impact of smoking and exposure to radon on lung cancer incidence, health care costs and all-cause deaths, with or without public health interventions. When simulating smoking behaviour, it attempts to replicate the smoking initiation rate of the Canadian population starting from age 15 years, as well as the quit rate and smoking intensity (light v. heavy smoker) observed in 3 large Canadian health surveys (1979 Canada Health Survey, 19941995 National Population Health Survey and 2008 Canadian Community Health Survey) (Appendix 1, section A, available at www.cmajopen.ca/content/8/3/E585/suppl/DC1). ${ }^{18-20}$

The tool models the change in smoking rates and intensity across time periods for each age group, by sex and province. For instance, age group 15-19 in 1979 corresponds to age group 30-34 in the 1994 survey (15 yr later) and age group 40-44 in 2004. Survey data from the 1970s are essential because most people eligible for lung cancer screening in 2020 (aged 55-74 yr) would have started smoking in the 1970s. In addition to the 3 surveys, the smoking initiation rates were calibrated to match the smoking prevalence by 5 -year age group, sex and province reported in the 2009 Canadian Community Health Survey. ${ }^{21}$ Thus, an eligible screening population that was as realistic as possible was replicated to serve as the basis for projections from 2020.

OncoSim-Lung models the impact of smoking history and radon exposure on lung cancer using published risk equations, and the model is calibrated to match the lung cancer incidence data from the Canadian Cancer Registry 22,23 (Appendix 1, section A). OncoSim-Lung underwent extensive validation testing to ensure that the assumptions in the model were acceptable to Canadian lung cancer experts and its projected cause-specific mortality reproduced the observed data in the Canadian Cancer Registry. For low-dose CT screening, baseline recruitment uptake was set at $40 \%$, with linear uptake over 10 years and a rate of adherence to subsequent scans of $70 \%$ (Table 1); the assumptions were based on inputs from those involved in planning implementation of lung cancer screening across Canada.

Since the uptake of lung cancer screening is Canada is unknown, we conducted a sensitivity analysis varying the uptake of screening. When projecting the effects of lung cancer screening, OncoSim-Lung reproduces the results of the National Lung Screening Trial quite closely, as well as other comparable lung cancer microsimulation models. ${ }^{17,24}$

\section{Statistical analysis}

\section{Smoking cessation}

The optimal smoking cessation intervention for participants of lung cancer screening is unknown. A recent review suggested 
that an intervention that includes several counselling visits with or without pharmacotherapy is more effective than lessintensive interventions, such as providing brochures or brief counselling. ${ }^{12}$ Given the uncertainty around the exact smoking cessation approach, we conducted extensive sensitivity analysis on the smoking cessation costs and quit rates. For the basecase scenario, we modelled a smoking cessation intervention that includes nicotine replacement therapy (nicotine replacement therapy patch + short-acting products), varenicline and 15 -minute weekly counselling sessions for 12 weeks. ${ }^{13,14}$ Participants of low-dose CT screening are offered the intervention, up to 10 times, at each screening round if they are still smoking. The number of smoking cessation interventions participants receive thus varies according to whether they continue to smoke and the number of screening rounds attended.

The long-term effectiveness of a smoking cessation intervention embedded in a low-dose CT screening program is currently unknown; cessation rates at 6-24 months have ranged from $8 \%$ to $20 \%$ in low-dose CT screening clinical studies. ${ }^{12}$ For the base-case scenario, we assumed that an optimized smoking cessation intervention would lead to a permanent quit rate of $2.5 \%$ per attempt, in addition to the average background quit rate of $3.6 \%$ per year, based on data from the 3 large national Canadian surveys. ${ }^{18-20} \mathrm{We}$ believed that a $2.5 \%$ quit rate would be achievable with an intervention that offers multiple sessions of counselling and pharmacotherapy. ${ }^{12-14,25} \mathrm{We}$ did not attempt to model short-term smoking cessation and relapses because reliable data are not available at this level of detail. Also, shortterm cessation is unlikely to have a lasting or major impact on long-term health outcomes (lung cancer or all-cause mortality).

The average total cessation rate achieved by integrating a smoking cessation intervention within the low-dose CT screening program is calculated as the number of smokers who quit as a result of the intervention divided by the total number of smokers entering the screening program (Appendix 1, Supplemental Table S1). In sensitivity analyses, we varied the quit rate per cessation attempt, number of cessation attempts and cost of the cessation intervention (Table 1).

\section{Cost-effectiveness}

We conducted the cost-effectiveness analysis from the perspective of a public health care system. Costs are reported in 2019 Canadian dollars. In addition to the costs of lung cancer screening and the smoking cessation intervention, OncoSim includes costs of lung cancer treatment, estimated with the use of administrative data for patients with lung cancer in Ontario, supplemented with expert opinion (Appendix 1, section C). ${ }^{15}$ The treatment costs included acute care, palliative care and end-of-life care.

The primary outcomes of this analysis are quality-adjusted life-years (QALYs) gained and incremental costs. We calculated QALYs using preference scores for the Canadian population and lung cancer health states (Appendix 1, section D). ${ }^{26,27}$ We discounted QALYs and costs at $1.5 \%$ annually on a lifetime horizon, as recommended in the latest Canadian guideline for health technology assessment. ${ }^{28} \mathrm{We}$ also provide undiscounted results and results discounted at 3\% to aid comparison with other studies.
Smoking cessation also affects the risk of death from causes other than lung cancer, such as myocardial infarction, stroke, chronic obstructive airway disease and other smoking-related illnesses. The reduced risk of death from these noncancer diseases is accounted for in the model. To characterize the joint uncertainty of the effectiveness and cost of a smoking cessation intervention, we conducted a probabilistic sensitivity analysis sampling the quit rate and cost of the intervention simultaneously 10000 times (Appendix 1, section E).

\section{Ethics approval}

Ethical approval was not required for this mathematical simulation.

\section{Results}

Offering a smoking cessation intervention in the context of annual lung cancer screening for people at high risk could potentially lead to an additional $13 \%$ of smokers quitting smoking permanently. On average, current smokers participating in lung cancer screening would receive the intervention 5 times. The model projected that adding the cessation intervention to low-dose CT screening could prevent 12 more cases of lung cancer and save 200 more life-years for every 1000 smokers screened compared to a screening program without a cessation intervention (Table 2).

\begin{tabular}{|c|c|}
\hline Variable & Result \\
\hline \multicolumn{2}{|l|}{$\begin{array}{l}\text { Outcome per } 1000 \text { people eligible for } \\
\text { smoking cessation intervention* }\end{array}$} \\
\hline No. of lung cancer cases prevented & 12 \\
\hline No. of life-years gained & 200 \\
\hline \multicolumn{2}{|l|}{$\begin{array}{l}\text { Outcome per } 1000 \text { people eligible for } \\
\text { smoking cessation intervention* } \\
\text { discounted at } 1.5 \% \text { per year }\end{array}$} \\
\hline Life-years gained & 130 \\
\hline QALYs gained & 98 \\
\hline Smoking cessation intervention costs, $\$$ & 2.8 million \\
\hline Incremental cost of lung cancer treatments, \$ & -600000 \\
\hline $\begin{array}{l}\text { Incremental total direct health care } \\
\text { costs, \$† }\end{array}$ & 2.2 million \\
\hline Incremental cost per QALY gained, \$ & 22200 \\
\hline \multicolumn{2}{|c|}{$\begin{array}{l}\text { Note: QALY = quality-adjusted life-year. } \\
\text { *Based on base-case screening program that assumes annual screening of } \\
\text { people aged 55-74 years with } 30 \text { pack-year or more smoking history, } 60 \% \\
\text { recruitment rate phased in over } 10 \text { years and rescreening adherence rate of } \\
70 \% \text {; base-case smoking cessation intervention assumes } 10 \text { cessation attempts } \\
\text { with } 2.5 \% \text { quit rate per attempt at a cost of } \$ 622 \text { per attempt. } \\
\text { tIncludes costs of smoking cessation intervention and lung cancer screening, } \\
\text { and direct health care costs of treating lung cancer. }\end{array}$} \\
\hline
\end{tabular}


Adding a smoking cessation intervention to lung cancer screening was estimated to cost \$22 000 per QALY gained (Table 2). Screening with a cessation intervention would cost less than $\$ 50000$ per QALY gained across a wide range of potential quit rates $(1 \%-10 \%$ per attempt) and smoking cessation attempts (3-20), except when the quit rate was $1 \%$ per attempt (Figure 1). In a threshold analysis, assuming the intervention cost $\$ 630$ per attempt and was offered up to 10 times to screening participants, the smoking cessation intervention cost less than $\$ 50000$ per QALY gained as long as the quit rate was at least $1.25 \%$ per attempt.

One-way sensitivity analyses showed that the costeffectiveness of the smoking cessation intervention improved with lower intervention costs and higher quit rates (Table 3). For example, at a quit rate per attempt of $10 \%$, adding a cessation intervention to lung cancer screening would lead to $41 \%$ of smokers quitting smoking over a lifetime and was highly cost-effective (incremental cost-effectiveness ratio \$600/ QALY gained). Assuming a cost-effectiveness threshold of $\$ 50000$ per QALY gained, adding a cessation intervention to lung cancer screening would be cost-effective as long as the intervention cost no more than $\$ 1249$ per attempt at a quit rate per attempt of $2.5 \%$ (Figure 2 ).

In a 2 -way sensitivity analysis, when we assumed that the quit rate changed according to the intensity of the intervention (with a range of $1 \%-10 \%$ for quit rate and $\$ 252-\$ 945$ for intervention cost), the incremental cost-effectiveness ratio ranged from $\$ 4000$ to $\$ 38000$ per QALY gained (Appendix 1, Supplemental Table S5). For example, a smoking cessation intervention that cost $\$ 378$ and led to 1 more smoker quitting permanently for every 100 attempts (1\% quit rate per attempt) would cost $\$ 38000$ per QALY gained.

In a probabilistic sensitivity analysis to characterize the joint uncertainty of quit rate and cost of the cessation intervention, screening with the intervention was cost-effective $80 \%$ of the time if the cost-effectiveness threshold was \$50 000 per QALY gained (Figure 3; Appendix 1, Supplemental Figure S1). Since the uptake of lung cancer screening is unknown, we simulated different recruitment and adherence rates. Changing the uptake of screening had little impact on the cost-effectiveness of screening with a smoking cessation intervention (Appendix 1, Supplemental Table S6).

\section{Interpretation}

In the context of annual lung cancer screening for people at high risk, adding a moderately effective smoking cessation intervention to low-dose CT screening could prevent 12 more lung cancers and save 200 more life-years for every 1000 smokers screened, as compared to a screening program

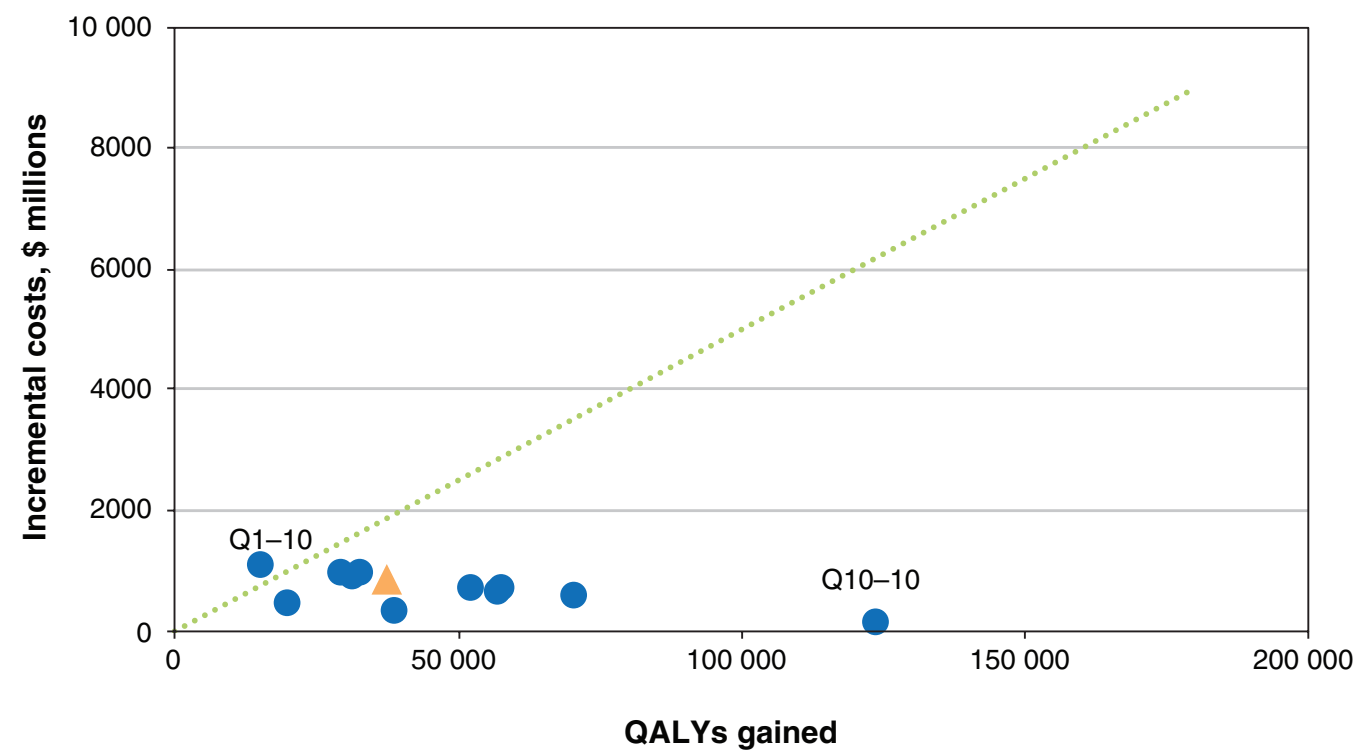

Figure 1: Incremental costs and quality-adjusted life-years (QALYs) gained for smoking cessation intervention (v. no smoking cessation intervention) at different quit rates and maximum cessation attempts (more results in Table 3 ), discounted at $1.5 \%$ per year, in a lung cancer screening program with a recruitment rate of $40 \%$ and a rescreening adherence rate of $70 \%$. Dotted line represents the cost-effectiveness threshold of $\$ 50000$ per QALY gained. All except the Q1-10 scenario are below the dotted line, which means that the smoking cessation intervention was cost-effective in almost all scenarios in which we varied the quit rates across the plausible range (more results in Table 3). Triangle represents the base case (2.5\% quit rate up to a maximum of 10 smoking cessation attempts). Q1-10 refers to a scenario with $1 \%$ quit rate in which the smoking cessation intervention was offered up to 10 times; this scenario had the highest incremental cost-effectiveness ratio (ICER) (\$68 000 per QALY gained). Q10-10 refers to a scenario with 10\% quit rate in which the smoking cessation intervention was offered up to 10 times; this scenario had the lowest ICER (\$600 per QALY gained). 


\section{Table 3: Incremental cost-effectiveness of incorporating a smoking cessation intervention into a lung cancer} screening program for selected smoking cessation scenarios*

\begin{tabular}{|c|c|c|c|}
\hline \multirow[b]{2}{*}{ Smoking cessation intervention assumptions } & \multicolumn{3}{|c|}{ ICER, \$† } \\
\hline & No discount & $\begin{array}{c}\text { Discounted at } \\
1.5 \%\end{array}$ & $\begin{array}{c}\text { Discounted at } \\
3.0 \%\end{array}$ \\
\hline Base case $\ddagger$ & 15700 & 22200 & 30400 \\
\hline \multicolumn{4}{|l|}{ Quit rate per attempt } \\
\hline \multicolumn{4}{|l|}{10 attempts } \\
\hline $1 \%$ for 10 attempts & 50100 & 67900 & 90000 \\
\hline $5 \%$ for 10 attempts & 4700 & 7700 & 11400 \\
\hline $10 \%$ for 10 attempts & Dominant & 600 & 2200 \\
\hline $2.5 \%$ for 5 attempts, then $1 \%$ for 5 attempts & 20000 & 27800 & 37400 \\
\hline $2.5 \%$ for 4 attempts, then $1 \%$ for 6 attempts & 22200 & 30600 & 41000 \\
\hline $5 \%$ for 5 attempts, then $1 \%$ for 5 attempts & 7500 & 11200 & 15800 \\
\hline $5 \%$ for 4 attempts, then $1 \%$ for 6 attempts & 9000 & 13100 & 18300 \\
\hline \multicolumn{4}{|l|}{3 attempts } \\
\hline $2.5 \%$ & 15400 & 22400 & 31300 \\
\hline $5 \%$ & 4600 & 7800 & 11800 \\
\hline \multicolumn{4}{|l|}{20 attempts } \\
\hline $2.5 \%$ for 5 attempts, then $1 \%$ for 15 attempts & 21400 & 29300 & 39000 \\
\hline $5 \%$ for 5 attempts, then $1 \%$ for 15 attempts & 8300 & 12100 & 16800 \\
\hline \multicolumn{4}{|l|}{ Cessation intervention cost } \\
\hline \multicolumn{4}{|l|}{$2.5 \%$ quit rate for 10 attempts } \\
\hline$\$ 252$ per attempt (40\% of base cost) & 3000 & 5000 & 8000 \\
\hline$\$ 378$ per attempt (60\% of base cost) & 7000 & 10800 & 15000 \\
\hline$\$ 756$ per attempt ( $120 \%$ of base cost) & 20000 & 28000 & 38000 \\
\hline$\$ 945$ per attempt ( $150 \%$ of base cost) & 26000 & 36600 & 49000 \\
\hline \multicolumn{4}{|l|}{$2.5 \%$ quit rate for 5 attempts, then $1 \%$ for 5 attempts } \\
\hline$\$ 252$ per attempt (40\% of base cost) & 4400 & 7200 & 10600 \\
\hline$\$ 378$ per attempt ( $60 \%$ of base cost) & 9600 & 14000 & 19500 \\
\hline$\$ 756$ per attempt ( $120 \%$ of base cost) & 25200 & 34600 & 46300 \\
\hline$\$ 945$ per attempt ( $150 \%$ of base cost) & 33000 & 44900 & 59600 \\
\hline \multicolumn{4}{|l|}{$5 \%$ quit rate for 10 attempts } \\
\hline$\$ 252$ per attempt ( $40 \%$ of base cost) & Dominant & Dominant & 300 \\
\hline$\$ 378$ per attempt (60\% of base cost) & 500 & 2000 & 4000 \\
\hline$\$ 756$ per attempt ( $120 \%$ of base cost) & 7000 & 11000 & 15000 \\
\hline$\$ 945$ per attempt ( $150 \%$ of base cost) & 10000 & 15000 & 21000 \\
\hline \multicolumn{4}{|l|}{$5 \%$ quit rate for 5 attempts, then $1 \%$ for 5 attempts } \\
\hline$\$ 252$ per attempt (40\% of base cost) & Dominant & 500 & 2,000 \\
\hline$\$ 378$ per attempt ( $60 \%$ of base cost) & 2100 & 4100 & 6600 \\
\hline$\$ 756$ per attempt ( $120 \%$ of base cost) & 10200 & 14800 & 20400 \\
\hline$\$ 945$ per attempt ( $150 \%$ of base cost) & 14300 & 20100 & 27300 \\
\hline \multicolumn{4}{|c|}{$\begin{array}{l}\text { Note: ICER = incremental cost-effectiveness ratio. } \\
\text { *Annual screening of people aged } 55-74 \text { years with } 30 \text { pack-year or more smoking history, } 40 \% \text { recruitment rate phased in over } 10 \text { years and } \\
\text { rescreening adherence rate of } 70 \% \text {. Unless stated otherwise, the base-case settings apply: cessation rate per attempt of } 2.5 \% \text { at a cost of } \$ 630 \text { per } \\
\text { attempt and maximum } 10 \text { attempts. } \\
\text { †Compared to screening with no smoking cessation intervention. Monte Carlo uncertainty leads to } 95 \% \text { confidence interval around ICERs of about } \\
\pm 3 \% \text { on average. } \\
\neq \text { Cessation rate per attempt of } 2.5 \% \text { at cost of } \$ 630 \text {, maximum } 10 \text { attempts. }\end{array}$} \\
\hline
\end{tabular}




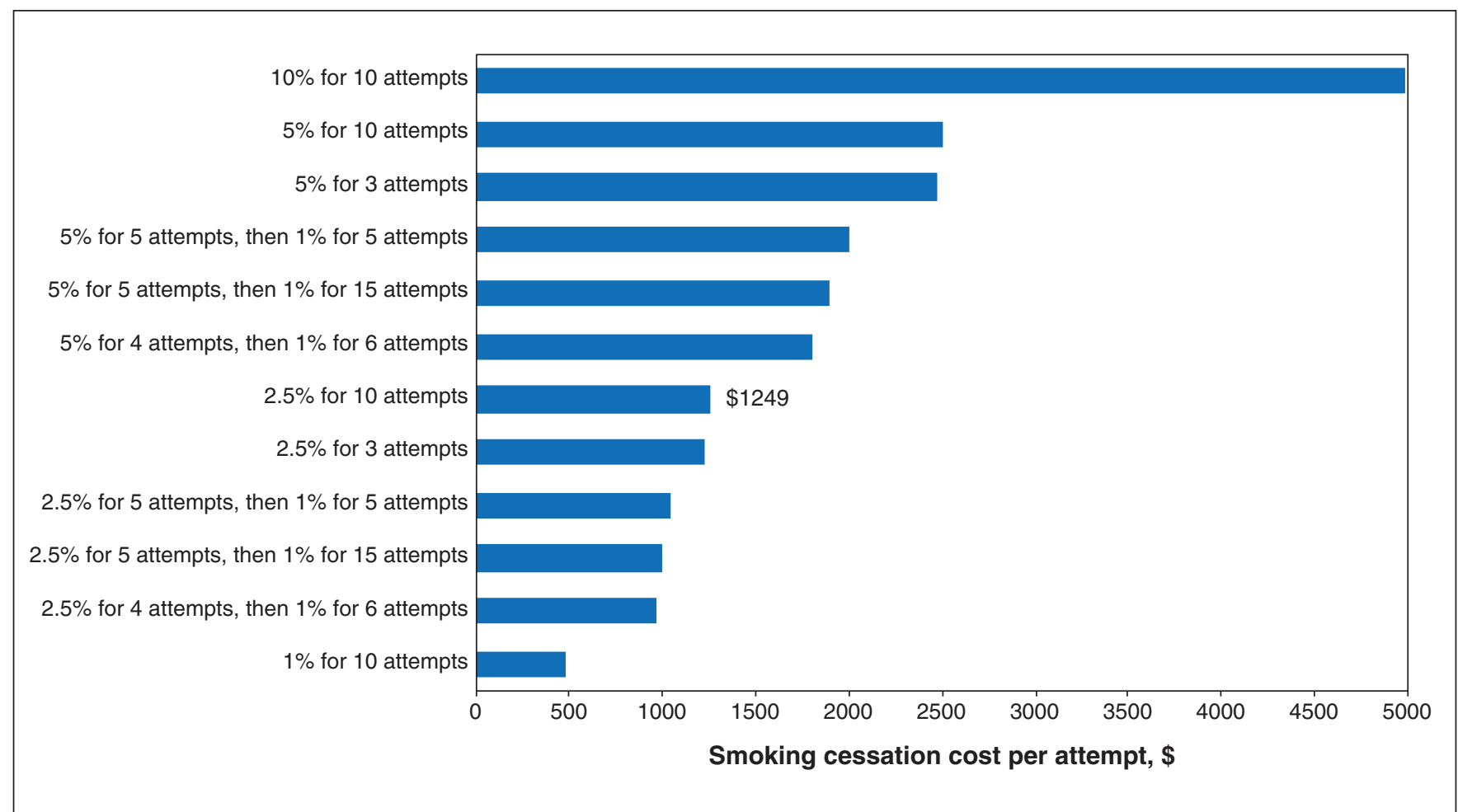

Figure 2: Cost-effectiveness thresholds of addition of smoking cessation intervention at different quit rates and maximum cessation attempts in a lung cancer screening program with recruitment rate of $40 \%$ and rescreening adherence rate of $70 \%$. Bars show the maximum cost of the intervention which the intervention was still cost-effective, assuming a cost-effectiveness threshold of \$50 000 per QALY gained. For example, in the base-case scenario (2.5\% permanent quit rate per attempt for up to 10 cessation attempts), the smoking cessation intervention would be cost-effective as long as it cost $\$ 1249$ or less per attempt. In the $1 \%$ for 10 attempts scenario, the intervention would be cost-effective as long as it cost $\$ 477$ or less per attempt.

without a cessation intervention. At a cost-effectiveness threshold of \$50 000 per QALY gained, integrating a smoking cessation intervention within a low-dose CT screening program would be cost-effective in most scenarios except when the permanent quit rate decreased from $2.5 \%$ to less than $1.25 \%$ per attempt, or when the intervention cost more than $\$ 1249$ with a $2.5 \%$ permanent quit rate per attempt. Our results support adding a smoking cessation intervention into a population-based lung cancer screening program in Canada.

Lung cancer screening in a high-risk population has been shown to reduce lung cancer mortality and is likely costeffective in Canada. ${ }^{2} 29-32$ Provinces and territories across Canada are currently planning or are in the early phase of implementing an organized lung cancer screening program. Adding a smoking cessation intervention to lung cancer screening may further reduce lung cancer mortality and could potentially improve the cost-effectiveness of lung cancer screening. ${ }^{9,32-34}$

Earlier analyses of low-dose CT screening did not focus on evaluating the cost-effectiveness of a smoking cessation intervention in the context of low-dose CT screening and included limited sensitivity analyses on key parameters. ${ }^{32-34}$ Our study aimed to fill this knowledge gap by evaluating the costeffectiveness of a smoking cessation intervention across a wide range of assumptions regarding the cost of an intervention and its effectiveness. Also, treatment patterns for advanced non-small-cell lung cancer have changed considerably in recent years with the introduction of immunotherapy and targeted oral therapy; our treatment costs reflect current treatment patterns in Canada. ${ }^{15,35}$

A recent review suggests that the effectiveness of a smoking cessation intervention for patients undergoing low-dose CT screening depends on the therapeutic intensity of the intervention. ${ }^{12}$ In particular, less-intensive interventions, such as providing brochures or brief counselling, did not appear to be sufficient; more-intensive interventions that included several counselling visits with or without various pharmacologic therapies appeared to be more effective. ${ }^{12}$ Our threshold analysis results show that a relatively less effective smoking cessation intervention that leads to only 1 participant quitting smoking for every 100 attempts (1\% quit rate per attempt) can still cost less than $\$ 50000$ per QALY gained as long as the intervention costs $\$ 477$ or less per attempt. For reference, the lowest-cost intervention we modelled was \$252, which would be considered a "more-intensive" intervention in the systematic review. ${ }^{12}$ More than 10 randomized clinical trials are currently underway to compare the effectiveness of smoking cessation interventions in the context of low-dose CT screening. ${ }^{10,12}$ Our sensitivity analysis includes the cost of different combinations of smoking cessation intervention and quit rates; therefore, our results are likely to be generalizable to future trial findings. 


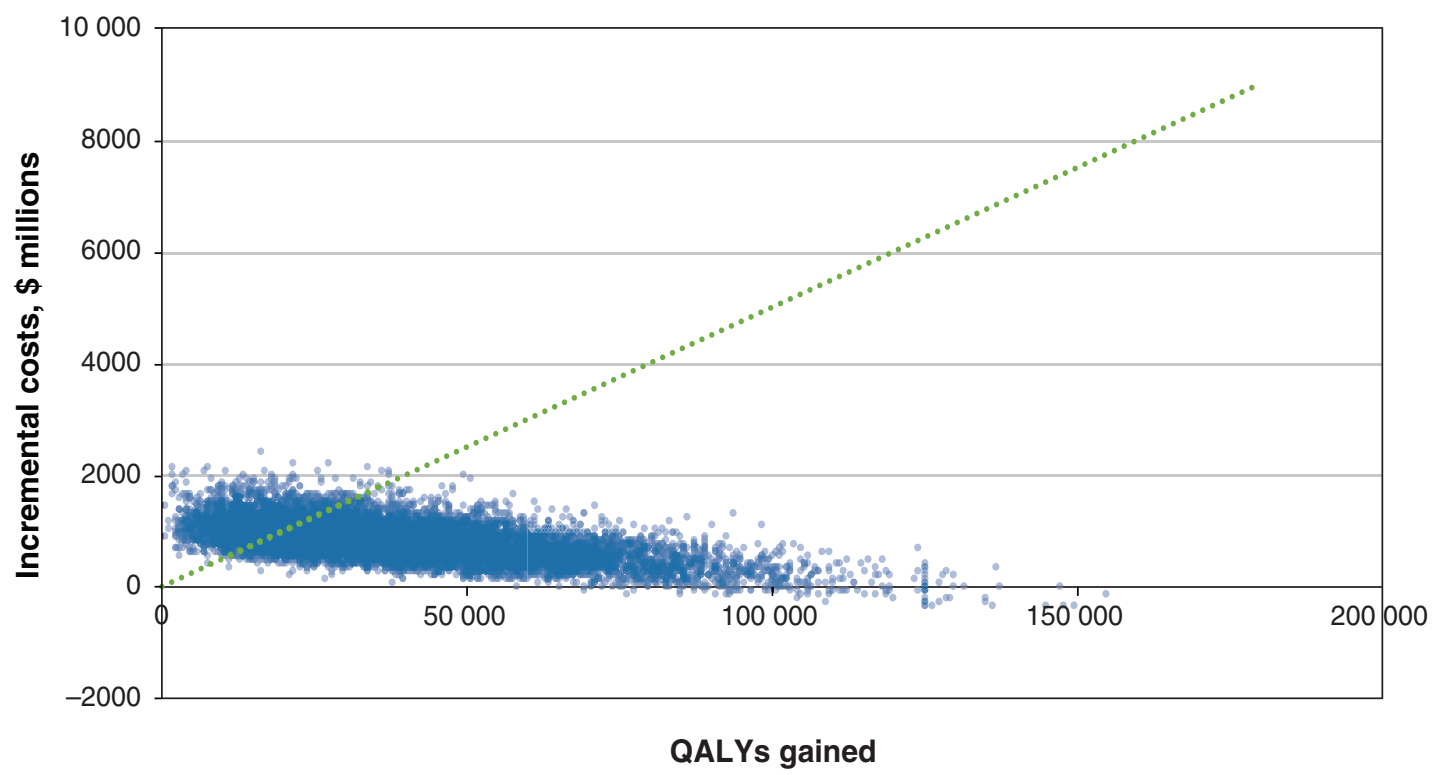

Figure 3: Results of probabilistic sensitivity analysis for a smoking cessation intervention that was offered up to 10 times to lung cancer screening participants in a lung cancer screening program with a recruitment rate of $40 \%$ and a rescreening adherence rate of $70 \%$. The graph shows the QALY gained and incremental costs for 10000 scenarios in which the quit rate and cost of the smoking cessation intervention were varied simultaneously. Each dot represents the results from 1 scenario (i.e., 1 combination of quit rate and cost of intervention [Appendix 1, section E]). Dotted line represents the cost-effectiveness threshold of $\$ 50000$ per QALY gained. At that threshold, the smoking cessation intervention was cost-effective $80 \%$ of the time ( $80 \%$ of dots are below dotted line).

\section{Limitations}

Our study has several limitations. First, the optimal smoking cessation intervention and the permanent quit rate achievable in a population-based low-dose CT screening program are unknown. ${ }^{12}$ Although the quit rate in pilot screening studies in Ontario is not yet known, it is encouraging to note that over $80 \%$ of participants accepted a referral to a smoking cessation service. ${ }^{36}$ Based on these considerations, we assumed a permanent quit rate of $2.5 \%$ per quit attempt (13\% cumulatively over lifetime) and conducted extensive sensitivity analysis on the cost and quit rate of a smoking cessation intervention. Second, we did not include any benefits that might be accrued by short-term cessation because reliable data are not available. Third, the model captures the benefits of smoking cessation on illnesses other than lung cancer, such as cardiovascular disease and chronic obstructive pulmonary disease, only through its impact on all-cause mortality. A smoking cessation intervention integrated with screening would have been more cost-effective if we had accounted for the improved quality of life and treatment costs saved through preventing complications from other illnesses, such as stroke, lung infections and heart failure.

\section{Conclusion}

Our model projections show that integrating a smoking cessation intervention into a low-dose CT screening program for lung cancer could further reduce the number of lung cancer cases and save more life-years, and is likely cost-effective compared to screening alone. To optimize the benefits of lung cancer screening, health care providers should encourage smokers participating in lung cancer screening to quit smoking at each visit.

\section{References}

1. Canadian Cancer Statistics Advisory Committee. Canadian cancer statistics 2017. Toronto: Canadian Cancer Society; 2017. Available: www.cancer.ca/ /media/ cancer.ca/CW/cancer\%20information/cancer\%20101/Canadian\%20cancer\% 20statistics/Canadian-Cancer-Statistics-2017-EN.pdf?la=en (accessed 2019 June 1).

2. The National Lung Screening Trial Research Team. Aberle DR, Adams AM, Berg CD, et al. Reduced lung-cancer mortality with low-dose computed tomographic screening. N Engl 7 Med 2011;365:395-409.

3. Canadian Task Force on Preventive Health Care. Recommendations on screening for lung cancer. CMA7 2016;188:425-32.

4. Manser RL, Irving LB, Byrnes G, et al. Screening for lung cancer: a systematic review and meta-analysis of controlled trials. Thorax 2003;58:784-9.

5. Moyer VA; U.S. Preventive Services Task Force. Screening for lung cancer: U.S. Preventive Services Task Force recommendation statement. Ann Intern Med 2014;160:330-8.

6. Taylor KL, Cox LS, Zincke N, et al. Lung cancer screening as a teachable moment for smoking cessation. Lung Cancer 2007;56:125-34.

7. van der Aalst CM, van der Bergh KA, Willemsen MC, et al. Lung cancer screening and smoking abstinence: 2-year follow-up data from the DutchBelgian randomized controlled lung cancer screening trial. Thorax 2010;65: 600-5.

8. Bach PB, Mirkin JN, Oliver TK, et al. Benefits and harms of CT screening for lung cancer: a systematic review. 7AMA 2012;307:2418-29.

9. Tanner NT, Kanodra NM, Gebregziabher M, et al. The association between smoking abstinence and mortality in the National Lung Screening Trial. Am 7 Respir Crit Care Med 2016;193:534-41. 
10. Joseph AM, Rothman AJ, Almirall D, et al. Lung Cancer Screening and Smoking Cessation Clinical Trials. SCALE (Smoking Cessation within the Context of Lung Cancer Screening) Collaboration. Am 7 Respir Crit Care Med 2018;197:172-82.

11. Lung cancer screening with low dose computed tomography: guidance for business case development. Toronto: Canadian Partnership Against Cancer; 2020. Available: https://www.partnershipagainstcancer.ca/topics/lung -screening-resources/ (accessed 2020 Mar. 25).

12. Iaccarino JM, Duran C, Slatore CG, et al. Combining smoking cessation interventions with LDCT lung cancer screening: a systematic review. Prev Med 2019;121:24-32.

13. Tulloch HE, Pipe AL, Els C, et al. Flexible, dual-form nicotine replacement therapy or varenicline in comparison with nicotine patch for smoking cessation: a randomized controlled trial. BMC Med 2016;14:80.

14. Mullen KA, Coyle D, Manuel D, et al. Economic evaluation of a hospitalinitiated intervention for smokers with chronic disease, in Ontario, Canada. Tob Control 2015;24:489-96.

15. Seung SJ, Hurry M, Hassan S, et al. Cost-of-illness study for non-small-cell lung cancer using real-world data. Curr Oncol 2019;26:102-7.

16. Evans WK, Wolfson M, Flanagan WM, et al. The evaluation of cancer control interventions in lung cancer using a Canadian cancer risk management model. Lung Cancer Manage 2012;1:25-33.

17. Flanagan WM, Evans WK, Fitzgerald NR, et al. Performance of the cancer risk management model lung cancer screening module. Health Rep 2015;26:11-8.

18. Canada Health Survey. Ottawa: Statistics Canada; 1979.

19. National Population Health Survey (NPHS). Ottawa: Statistics Canada; 1994/95.

20. Canadian Community Health Survey. Ottawa: Statistics Canada; 2008.

21. Canadian Community Health Survey. Ottawa: Statistics Canada; 2009.

22. Whittemore AS, McMillan A. Lung cancer mortality among U.S. uranium miners: a reappraisal. 7 Natl Cancer Inst 1983;71:489-99.

23. Tammemägi MC, Church TR, Hocking WG, et al. Evaluation of the lung cancer risks at which to screen ever- and never-smokers: screening rules applied to the PLCO and NLST cohorts. PLoS Med 2014;11:e1001764.

24. de Koning HJ, Meza R, Plevritis SK, et al. Benefits and harms of computed tomography lung cancer screening programs for high-risk populations. Rockville (MD): Agency for Healthcare Research and Quality; 2013.

25. Cromwell J, Bartosch WJ, Fiore MC, et al. Cost-effectiveness of the clinical practice recommendations in the AHCPR guideline for smoking cessation. Agency for Health Care Policy and Research. FAMA 1997;278:1759-66.

26. Guertin JR, Feeny D, Tarride JE. Age-and sex-specific Canadian utility norms, based on the 2013-2014 Canadian Community Health Survey. CMA72018;190:E155-61.

27. Boswell-Purdy J, Flanagan WM, Roberge H, et al. Population health impact of cancer in Canada, 2001. Chronic Dis Can 2007;28:42-55.

28. Guidelines for the economic evaluation of health technologies: Canada. 4th ed. Ottawa: Canadian Agency for Drugs and Technologies in Health; 2017.

29. Cressman S, Peacock SJ, Tammemägi MC, et al. The cost-effectiveness of high-risk lung cancer screening and drivers of program efficiency. 7 Thorac Oncol 2017;12:1210-22.

30. Marshall D, Simpson KN, Earle CC, et al. Potential cost-effectiveness of onetime screening for lung cancer (LC) in a high-risk cohort. Lung Cancer 2001; $32: 227-36$
31. Ten Haaf K, Tammemagi MC, Bondy SJ, et al. Performance and costeffectiveness of computed tomography lung cancer screening scenarios in a population-based setting: a microsimulation modeling analysis in Ontario, Canada. PLoS Med 2017;14:e1002225.

32. Goffin JR, Flanagan WM, Miller AB, et al. Cost-effectiveness of lung cancer screening in Canada. FAMA Oncol 2015;1:807-13.

33. Goffin JR, Flanagan WM, Miller AB, et al. Biennial lung cancer screening in Canada with smoking cessation - outcomes and cost-effectiveness. Lung Cancer 2016;101:98-103.

34. Villanti AC, Jiang Y, Abrams DB, et al. A cost-utility analysis of lung cancer screening and the additional benefits of incorporating smoking cessation interventions. PLoS One 2013;8:e71379.

35. Moldaver D, Hurry M, Evans WK, et al. Development, validation and results from the impact of treatment evolution in non-small cell lung cancer (iTEN) model. Lung Cancer 2020;139:185-94.

36. Evans WK, Darling G, Cameron E, et al. Acceptance of smoking cessation services in Cancer Care Ontario's lung cancer screening pilot for people at high risk [abstract]. Proceedings from the 19th World Conference on Lung Cancer; 2018 Sept. 23-26; Toronto, Ont.

Affiliations: Department of Oncology (Evans, Goffin), McMaster University, Hamilton, Ont.; Canadian Partnership Against Cancer (Gauvreau, Memon, Yong, Fitzgerald), Toronto, Ont.; Statistics Canada (Flanagan); Faculties of Medicine and Law (Wolfson), University of Ottawa, Ottawa, Ont.; Department of Public Health Sciences (Miller), University of Toronto, Toronto, Ont.

Contributors: Michael Wolfson and Anthony Miller supervised the project. William Evans, Cindy Gauvreau, Jean Yong, Natalie Fitzgerald and Michael Wolfson contributed to the study conception. William Evans, Cindy Gauvreau, William Flanagan, Jean Yong, John Goffin and Michael Wolfson contributed to the study design. William Evans, Cindy Gauvreau, William Flanagan, Jean Yong and Michael Wolfson analyzed the data. William Evans drafted the manuscript, and he and Cindy Gauvreau, William Flanagan, Saima Memon, Jean Yong, John Goffin, Michael Wolfson and Anthony Miller revised it critically for important intellectual content. All of the authors interpreted the data, approved the final version to be published and agreed to be accountable for all aspects of the work.

Funding: OncoSim is led and supported by the Canadian Partnership Against Cancer, with model development by Statistics Canada, and is made possible through funding from Health Canada.

Supplemental information: For reviewer comments and the original submission of this manuscript, please see www.cmajopen.ca/content/8/3/ E585/suppl/DC1. 